\title{
Numeric Validation of 3D Printer Technology Applied to Story Isolation on Tall Buildings
}

\author{
Luca Gallanti \\ MS., Civil Engineering Department, University of San Marino, Repubblic of San Marino, \\ 47890. E-mail: luca.gallanti@unirsm.sm \\ Davide Forcellini \\ Dr., Civil Engineering Department, University of San Marino, Repubblic of San Marino, 47890 (corresponding author). \\ E-mail: davide.forcellini@unirsm.sm
}

\begin{abstract}
Isolation technique on tall buildings is becoming increasingly common in large urban centers in order to ensure structural integrity and performance. In particular, while base isolation allows to decouple the structure from the ground considering the entire structure as a unique block, story isolation is able to separate upper levels from lower parts. It consists of intentionally concentrating seismic energy dissipation in interfaces between selected parts of the structures in order to interrupt the flux of energy between stories. In literature there are applications that demonstrate this principle without conducing lab tests because of extreme costs. In this paper, 3D printer new technology has been applied in order to reproduce on a small shake table scaled representative 3D models of a 20 stories tall building. The models have been then performed with numerical simulations in order to understand if 3D printer technology can be applied in this kind of research.
\end{abstract}

\section{Introduction}

Base isolation is a well-known technique in building arena, even if its effectiveness generally reduces with superstructure flexibility, as known in literature (Skinner et. al. 1993 and Pan and Cui 1994). These authors showed that its application should be limited to only buildings in the low to medium-rise range. However, the possibility to separate levels of structures is fundamentally important especially in multifunctional tall buildings where various parts have different functions and seismic performance requirements.

Story isolation technique consists of intentionally concentrating seismic energy dissipation in strategic locations dividing selected parts of the structures in order to interrupt the flux of energy between upper and lower stories. In literature there are applications that demonstrate this principle such as Ogura et. al, 1999, Murakami et al. 2000, Zhou et al. 2004, Xu et al. 2004 and Tsuneki et al. 2008, Tasaka et al 2008 and Chang et al. 2009. These contributes show story isolation effects in diffusing flexibility along the height of the building and thus reducing seismic forces. Pan et al. 1995, Pan and Cui 1998 considered segmental buildings, consisting in introducing more than one interface over the height of the building. Chey et al. 2013, Villaverde, 2002, Villaverde et al. 2005 and Ziyaeifar and Noguchi, 1998 considered applications of isolation technique on the top of existing structures by adding tuned mass damper (TMD) systems. Other researchers, such as Koh and Kobayashi, 2000, Li et al., 2002, Pochas and Pamboris, 2009, Desai Amit and Gajjar, 2012 and Charmpis et al. 2015 investigated story isolated structures with numerical simulations demonstrating that base isolation 
effectiveness reduces with superstructure flexibility. Despite these contributions, none of these investigated behaviors through lab tests because of extreme costs.

This paper shows the reproduction on a small indoor shake table scaled representative 3D models of a 20 -story steel moment-resisting benchmark building. In particular, appropriate dynamic properties such as frequencies and shape modes have been calculated and verified. Thanks to its versatility, it was possible to introduce more than one interface representing isolation interfaces in key locations. This allows to consider superior shape modes associated with low frequencies and to investigate the role of structural flexibility. Interfaces have been introduced in several locations over the height of the building in order to assess the best performance between various configurations. The models are then reproduced with numerical simulations in order to validate the applied 3D printer technology. Comparison between numerical models and lab test models response in terms of fundamental periods and top floor accelerations showed good agreement.

\section{Models}

The original structure is a 20 story steel (ASTM A992) moment-resisting benchmark building (Figure 1). Sections are detailed in Table 1 and Table 2. A 2D model (named B0) has been simplified in order to have the same dynamic characteristics for each floor and performed with SAP 2000. A second model (named M0) has been performed in order to simplify the original structure with 4 degree of freedom and help to build the final lab test model (named L0). Figure 2 shows the three models used in this study: a schematic view of the building (B0 model), the corresponding 4 DOF (M0 model) built up with 4 modules representing 5 stories and the lab test (L0 model).

M models have been built considering a scale-up procedure, following theoretical approach by Kline, S. J. (1986). In particular, geometrical similitude has been taken into account, by imposing B0 and M0 model to have the same top displacements $\left(\mathrm{u}_{4}^{\mathrm{M}}=\mathrm{u}_{20}^{\mathrm{B}}\right)$. Stiffness has been assigned to vertical elements $(0.3066 \mathrm{~m} \mathrm{x}$ $0.3066 \mathrm{~m}$ square cross section) and masses have been concentrated in correspondence with floor 5, 10, 15 and 20. Equivalent lateral stiffness $\left(\mathrm{k}_{\mathrm{eq}}=22000 \mathrm{kN} / \mathrm{m}\right)$ and Equivalent masses $\left(\mathrm{m}_{\mathrm{eq}}=192 \mathrm{kN}\right)$ have been defined by applying seismic forces and calculating the corresponding seismic reactions with a rotational balance at the base of the model. Story displacements have been finally calculated and compared. Maximum mistake has found to be around $15 \%$.

L models have been printed with a 3D printer (Makerbot Replicator 2X, http://www.makerbot.com) adopting $1.75 \mathrm{~mm}$ filament types. They have been defined following Kline, S. J. (1986) theory and considering geometrical similitude. Each five modulus $(10 \mathrm{~cm} \times 6.5 \mathrm{~cm} \times 6.5 \mathrm{~cm}$, Figure 3) has been characterized by a 10 x $10 \mathrm{~mm}$ cross section with respectively $1.30 \mathrm{~kg}$ mass and $1700 \mathrm{~N} / \mathrm{m}$ lateral stiffness. These values have been verified with a pushover device able to evaluate force displacement relations. Figure 4 shows the tested results (with blue points) and the calculated linear interpolation. In order to verify the correct scaling of B0, M0 and L0 models, dynamic characteristics (in terms of natural frequencies and periods) have been calculated and shown in Table 3. 


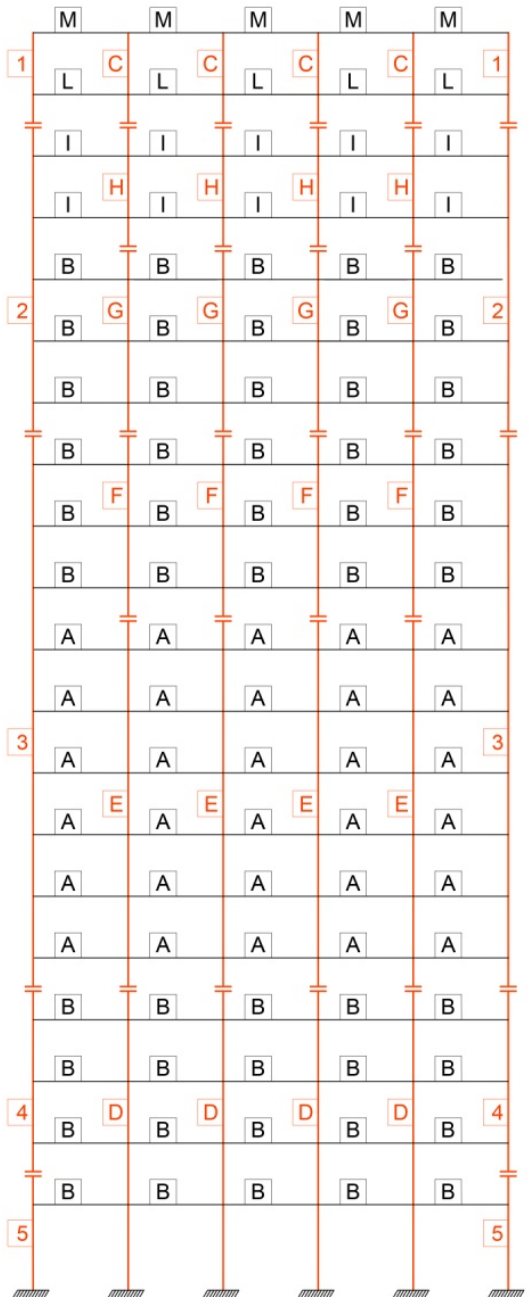

Figure 1. Case study.

Table 1

$W$ section characteristics (Beam sections)

\begin{tabular}{lllll}
\hline Section & Height & Flanges Width [m] & Flanges Thickness & Web Thickness [m] \\
\hline A & 0.7577 & 0.2661 & 0.0193 & 0.0138 \\
B & 0.7544 & 0.2667 & 0.0170 & 0.0132 \\
C & 0.6784 & 0.2530 & 0.0163 & 0.0117 \\
D & 0.6990 & 0.3434 & 0.0630 & 0.0351 \\
E & 0.6609 & 0.3330 & 0.0439 & 0.0244 \\
F & 0.6469 & 0.3289 & 0.0371 & 0.0206 \\
G & 0.6218 & 0.3265 & 0.0244 & 0.0154 \\
H & 0.6162 & 0.3251 & 0.0216 & 0.0140 \\
I & 0.6121 & 0.2291 & 0.0196 & 0.0119 \\
L & 0.6030 & 0.1788 & 0.0150 & 0.0109 \\
M & 0.5291 & 0.1659 & 0.0136 & 0.0096 \\
\hline
\end{tabular}


Table 2

Box section characteristics

\begin{tabular}{lllll}
\hline Section & & Height & Width & Thickness \\
\hline 1 & $15 \times 15 X 0.5$ & 0.381 & 0.381 & 0.0127 \\
2 & $15 X 15 X 0.75$ & 0.381 & 0.381 & 0.0191 \\
3 & $15 X 15 X 1$ & 0.381 & 0.381 & 0.0254 \\
4 & $15 X 15 X 1.25$ & 0.381 & 0.381 & 0.0318 \\
5 & $15 X 15 X 2$ & 0.381 & 0.381 & 0.0508 \\
\hline
\end{tabular}

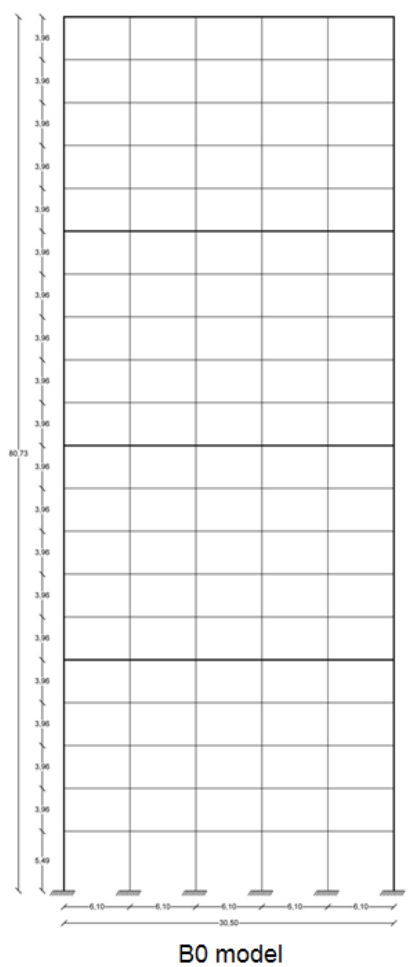

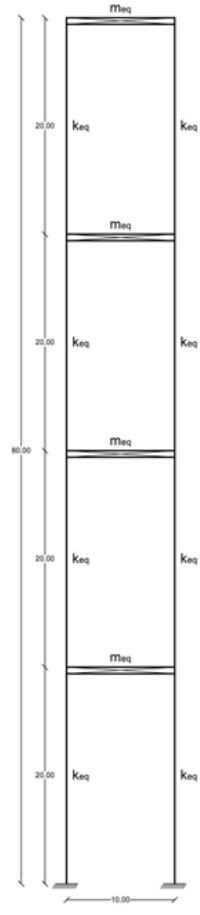

MO model

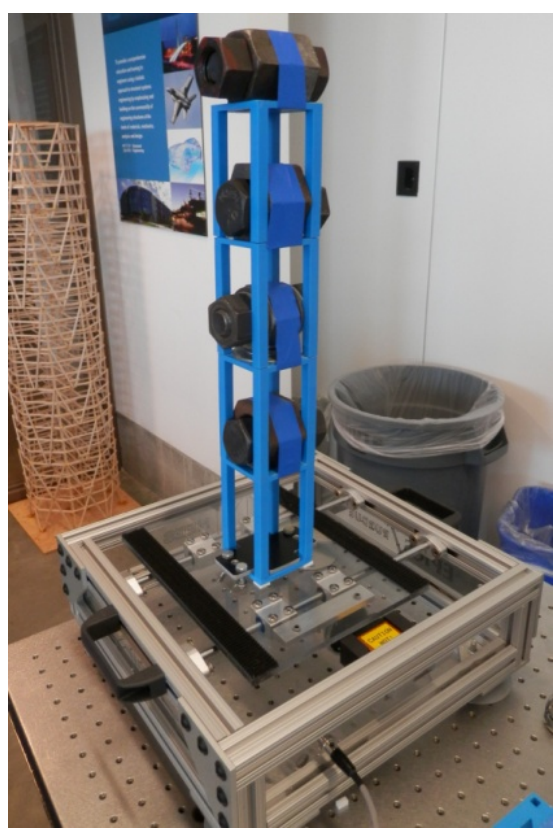

LO model

Figure 2. B0, M0 and L0 models.
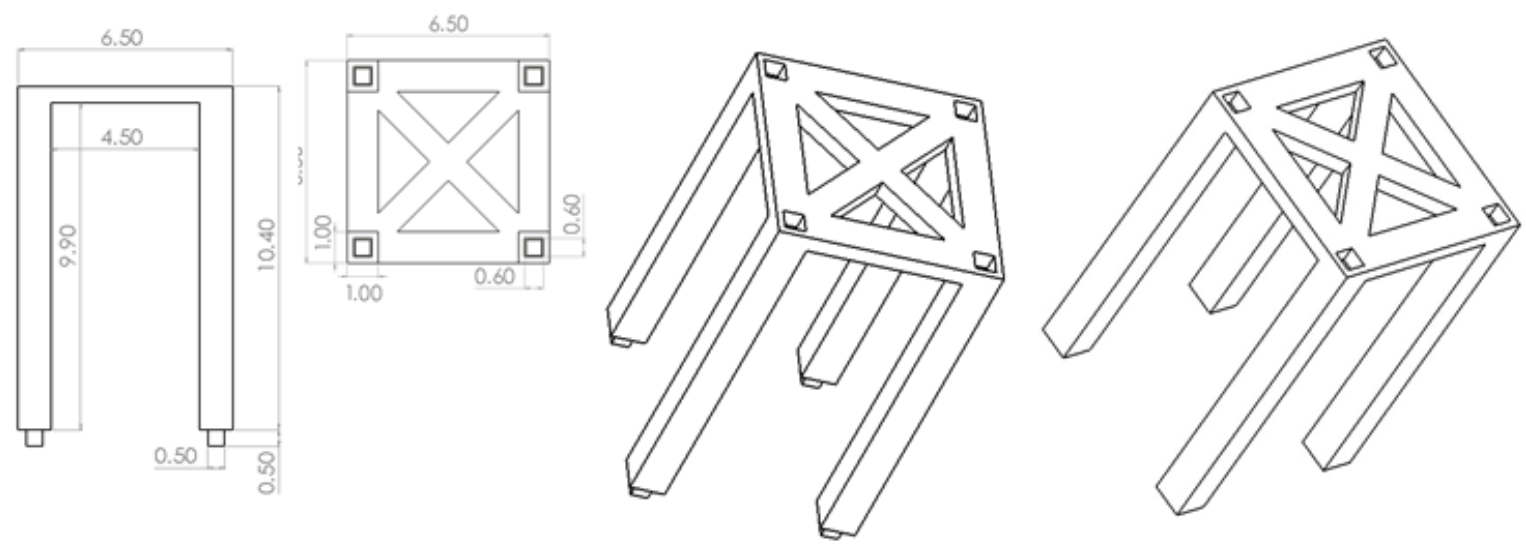

Figure 3. Modules geometry. 


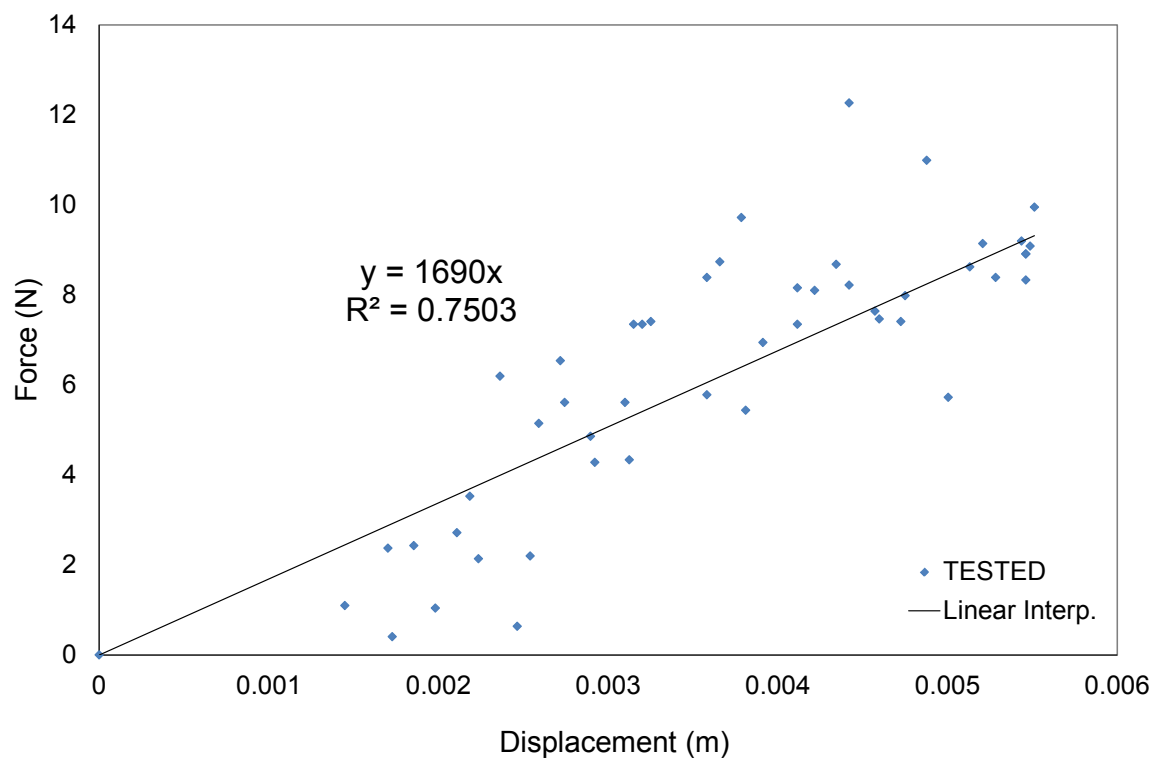

Figure 4. Pushover response.

Table 3

Comparison between B0, M0, L0 model periods

\begin{tabular}{lllll}
\hline & $\mathrm{T}_{1}[\mathrm{~s}]$ & $\mathrm{T}_{2}[\mathrm{~s}]$ & $\mathrm{T}_{3}[\mathrm{~s}]$ & $\mathrm{T}_{4}[\mathrm{~s}]$ \\
\hline B0 & 0.508 & 0.172 & 0.104 & 0.074 \\
M0 & 0.534 & 0.185 & 0.121 & 0.088 \\
L0 & 0.500 & 0.170 & 0.110 & 0.090 \\
\hline
\end{tabular}

Modules have been built with holes at the base where it is possible to insert connectors (rigid or flexible) in order to simulate fixed connections or isolated devices respectively. Isolation connections (story interfaces) have been printed with TPE (thermoplastic elastomer) flexible filament by Ninjaflex (www.3ders.org). These interfaces have been modelled adopting linear assumptions and neglecting damping, following Kelly (1997) and Forcellini and Kelly (2014). Several story configurations have been built by introducing connections along the height of L model (details in the next section). They have been all tested on an indoor shake table named "Quanser Shake Table II" (http://www.quanser.com/products/shake_table_II) at University of California San Diego.

\section{Configurations}

Modules versatility allows the introduction of several connectors able to simulate isolation interfaces or fixed connections in key locations along the height of the building. In particular, six configuration have been investigated as to increase structural flexibility by considering superior modes. In particular, isolation interfaces (represented in Figure 5 with red horizontal lines) have been introduced in those positions where model shape modes show inflection points. The main goal is to assess the best performance between several configurations by considering both reduction in seismic forces and increase in structural flexibility. 


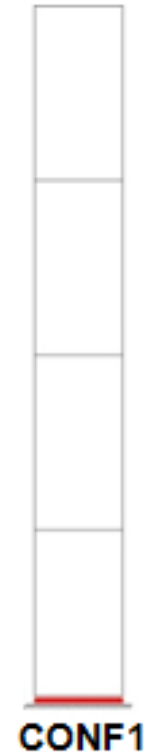

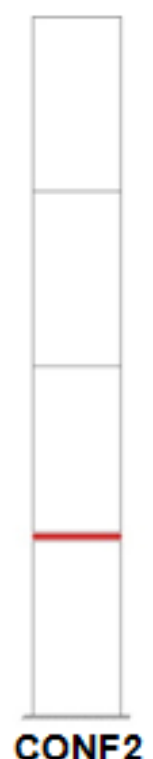

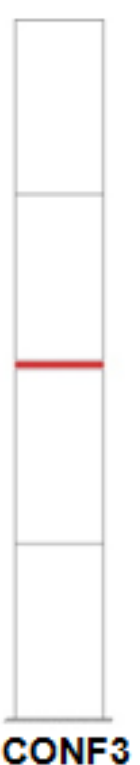

CONF3
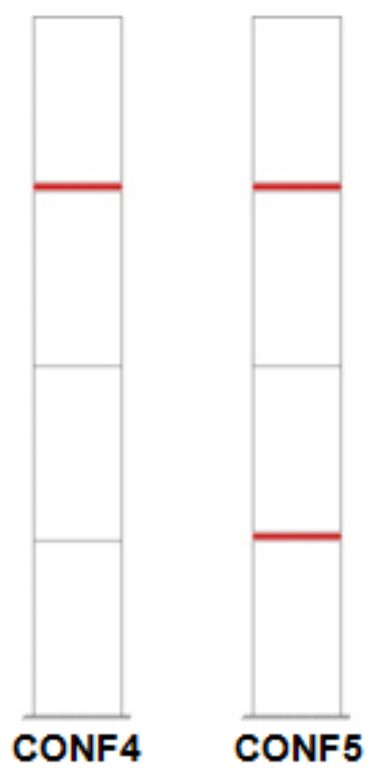

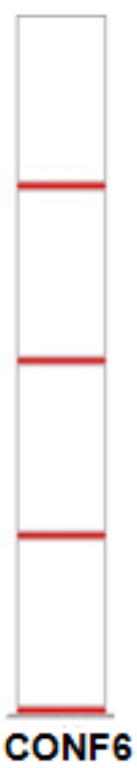

Figure 5. Model configurations.

In particular, configurations 1 (L1 and B1) represent base isolation, 2 and 3 (L2, L3 and B2, B3) story isolations, 4 (L4 and B4) added stories configurations and finally, 5 and 6 (L5, L6 and B5, B6) segmental buildings. Isolation devices have been represented by longitudinal linear springs ( $\mathrm{k}=12000 \mathrm{kN} / \mathrm{m})$ calibrated in order to increase the first $\mathrm{B} 0$ and $\mathrm{B} 1$ periods from $0.508 \mathrm{~s}$ to $0.563 \mathrm{~s}$ (around $10 \%$, Table 5). L model connectors stiffness has been chosen in order to have the same effects in the periods and calibrated with the theoretical approaches proposed by Kelly, J.M., 1997. In particular, L model fundamental periods (Table 4) have been tested on the NEES Instructional Shake Table (https://nees.org/resources/7623, Figure 2), at University of California San Diego.

For B models and M models, fundamental periods have been analytically calculated and validated with SAP2000 (modal analysis). Table 5 and 6 show the first four fundamental periods calculated for B models and $\mathrm{M}$ models respectively. Table 7 shows modal participation mass ratios for the first four fundamental periods calculated for B models. Table 8 shows ratios between first four fundamental periods calculated for models B and models L. It is possible to see that there is a good agreement between the fundamental periods of the first modes, meaning that $3 \mathrm{D}$ printed modulus are able to represent the original structure.

Table 4

Fundamental periods for 7 configurations (L Models)

\begin{tabular}{lllll}
\hline & $\mathrm{T}_{1}[\mathrm{~s}]$ & $\mathrm{T}_{2}[\mathrm{~s}]$ & $\mathrm{T}_{3}[\mathrm{~s}]$ & $\mathrm{T}_{4}[\mathrm{~s}]$ \\
\hline L0 & 0.500 & 0.170 & 0.110 & 0.090 \\
L1 & 0.550 & 0.200 & 0.130 & 0.100 \\
L2 & 0.550 & 0.220 & 0.150 & 0.120 \\
L3 & 0.200 & 0.150 & 0.120 \\
L4 & 0.550 & 0.180 & 0.150 & 0.100 \\
L5 & 0.500 & 0.220 & 0.150 & 0.100 \\
L6 & 0.550 & 0.220 & 0.150 & 0.120 \\
\hline
\end{tabular}


Table 5

Fundamental periods for 7 configurations (B Models)

\begin{tabular}{lllll}
\hline & $\mathrm{T}_{1}[\mathrm{~s}]$ & $\mathrm{T}_{2}[\mathrm{~s}]$ & $\mathrm{T}_{3}[\mathrm{~s}]$ & $\mathrm{T}_{4}[\mathrm{~s}]$ \\
\hline B0 & 0.508 & 0.172 & 0.104 & 0.074 \\
B1 & 0.563 & 0.200 & 0.115 & 0.082 \\
B2 & 0.537 & 0.179 & 0.104 & 0.076 \\
B3 & 0.174 & 0.116 & 0.075 \\
B4 & 0.519 & 0.193 & 0.104 & 0.080 \\
B5 & 0.497 & 0.204 & 0.105 & 0.081 \\
B6 & 0.552 & 0.222 & 0.133 & 0.095 \\
\hline
\end{tabular}

Table 6

Fundamental periods for 7 configurations (M Models)

\begin{tabular}{lllll}
\hline & $\mathrm{T}_{1}[\mathrm{~s}]$ & $\mathrm{T}_{2}[\mathrm{~s}]$ & $\mathrm{T}_{3}[\mathrm{~s}]$ & $\mathrm{T}_{4}[\mathrm{~s}]$ \\
\hline M0 & 0.534 & 0.185 & 0.121 & 0.088 \\
M1 & 0.577 & 0.196 & 0.125 & 0.099 \\
M2 & 0.572 & 0.193 & 0.132 & 0.103 \\
M3 & 0.566 & 0.201 & 0.124 & 0.106 \\
M4 & 0.561 & 0.195 & 0.132 & 0.102 \\
M5 & 0.623 & 0.270 & 0.157 & 0.112 \\
M6 & 0.742 & 0.280 & 0.207 & 0.131 \\
\hline
\end{tabular}

Table 7

Modal participation mass ratio (\%) (B Models)

\begin{tabular}{lllll}
\hline$\%$ & $\mathrm{~T}_{1}[\mathrm{~s}]$ & $\mathrm{T}_{2}[\mathrm{~s}]$ & $\mathrm{T}_{3}[\mathrm{~s}]$ & $\mathrm{T}_{4}[\mathrm{~s}]$ \\
\hline B0 & 78.5 & 11.6 & 3.7 & 2.0 \\
B1 & 83.5 & 10.7 & 2.9 & 1.2 \\
B2 & 82.2 & 6.2 & 2.3 & 4.3 \\
B3 & 77.6 & 12.4 & 3.6 & 1.1 \\
B4 & 77.6 & 11.9 & 4.3 & 1.1 \\
B5 & 80.2 & 7.7 & 3.4 & 2.1 \\
B6 & 81.5 & 9.9 & 4.1 & 3.2 \\
\hline
\end{tabular}

Table 8

Fundamental period ratios (B/L Models)

\begin{tabular}{lllll}
\hline$\%$ & $\mathrm{~T}_{1}[\mathrm{~s}]$ & $\mathrm{T}_{2}[\mathrm{~s}]$ & $\mathrm{T}_{3}[\mathrm{~s}]$ & $\mathrm{T}_{4}[\mathrm{~s}]$ \\
\hline $\mathrm{L} 0 / \mathrm{B} 0$ & 0.98 & 0.95 & 1.06 & 1.22 \\
$\mathrm{~L} 1 / \mathrm{B} 1$ & 0.98 & 1.00 & 1.13 & 1.22 \\
$\mathrm{~L} 2 / \mathrm{B} 2$ & 1.02 & 1.23 & 1.44 & 1.58 \\
$\mathrm{~L} 3 / \mathrm{B} 3$ & 1.06 & 1.15 & 1.29 & 1.60 \\
$\mathrm{~L} 4 / \mathrm{B} 4$ & 1.01 & 0.93 & 1.44 & 1.23 \\
$\mathrm{~L} 5 / \mathrm{B} 5$ & 1.00 & 1.08 & 1.43 & 1.23 \\
$\mathrm{~L} 6 / \mathrm{B} 6$ & 1.00 & 0.99 & 1.13 & 1.26 \\
\hline
\end{tabular}




\section{Dynamic Analysis}

Models have been subjected to two input motions named CNP and LAC (Figure 6 and Figure 7 show acceleration time histories and spectra), selected in order to have the main frequencies close to the original B0 building fundamental frequencies. In particular, input motions have been applied assuming fixed base conditions (soil structure interaction effects neglected). Several responses have been considered in the study. During L models tests, one accelerometer has been set in correspondence with the top floor and registered top story accelerations time histories. $\mathrm{B}$ and $\mathrm{M}$ models have been performed with numerical simulations in Sap2000 in order to perform accelerations, displacements and drift ratios for each floor. The aim is to compare $\mathrm{L}$ and $\mathrm{B}$ configurations by assessing their behaviour in transferring seismic forces along the height and thus their seismic performance. Results are shown in the next section.
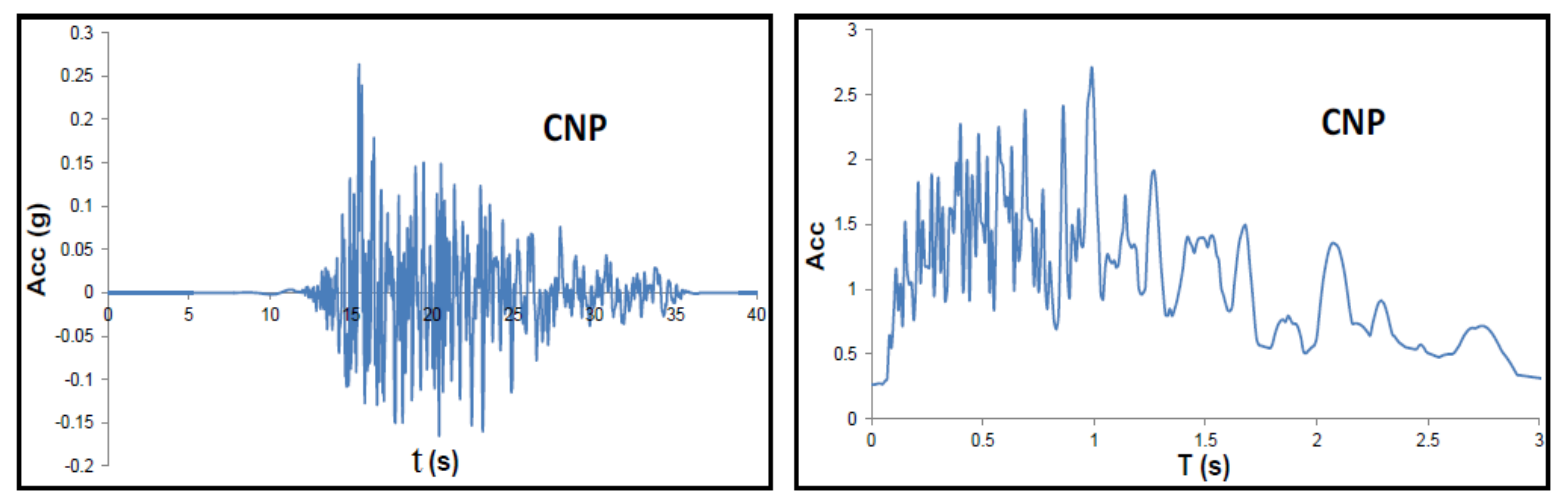

Figure 6. Input motion 1: CNP.
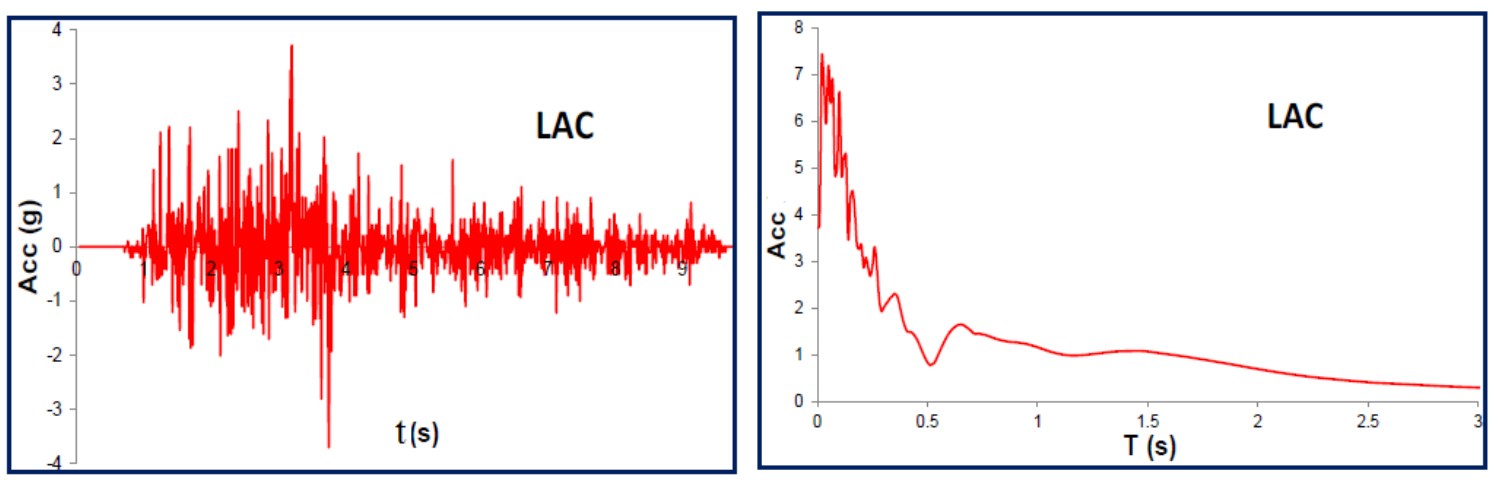

Figure 7. Input motion 2: LAC.

\section{Results}

This section describes comparisons between story isolated configurations, fixed based and based isolated configurations in terms of accelerations and displacements.

\section{Accelerations}

The role of story isolation is here assessed by considering its benefits in terms of accleration reduction when compared with base isolation. Figure 8 shows amplification factor (AF) defined as the ratio between maximum top floor accelerations and peak ground accelerations (PGA) for L1-L4 and B1-B4 models. Vertical axes represent the various configurations $(\mathrm{C} 1, \mathrm{C} 2, \mathrm{C} 3$ and $\mathrm{C} 4)$. The values have been plotted in correspondence 
with the heights where the interfaces are located. Values have been scaled with top accelerations registered in correspondence with fixed base (FB) configurations, represented with blue vertical lines. First of all, a close relationship between $\mathrm{L}$ and $\mathrm{B}$ top floor maximum accelerations can be seen. This means that lab models $\mathrm{L}$ are representative of real building B. Secondly, if compared with fixed base (FB) and base isolated configurations $(\mathrm{C} 1)$, story isolated configurations $(\mathrm{C} 2, \mathrm{C} 3$ and $\mathrm{C} 4)$ show improvement in reducing seismic accelerations (and consequently forces) on the building.

Table 9 and 10 show ratios between various models top pseudo-accelerations with the original non isolated model for CNP and LAC motions. As predicted, accelerations are shown to be smaller when superstructure flexibility increases. In case of story isolated configurations (L2, B2 and L3, B3), they are smaller if compared with those related with base isolated configurations (respectively L1 and B1). Moreover, configurations 4 (added stories) do not seem having great effects in reducing top accelerations. Segmental buildings (L5, B5 and L6, B6) register smaller accelerations if compared with other configurations. In particular, if configurations 5 and 6 are compared, it is possible to understand how the presence of a isolation level in the middle of the structure helps increasing flexibility and thus reducing accelerations. Therefore, it is possible to assess that configuration 6 has the best performance.
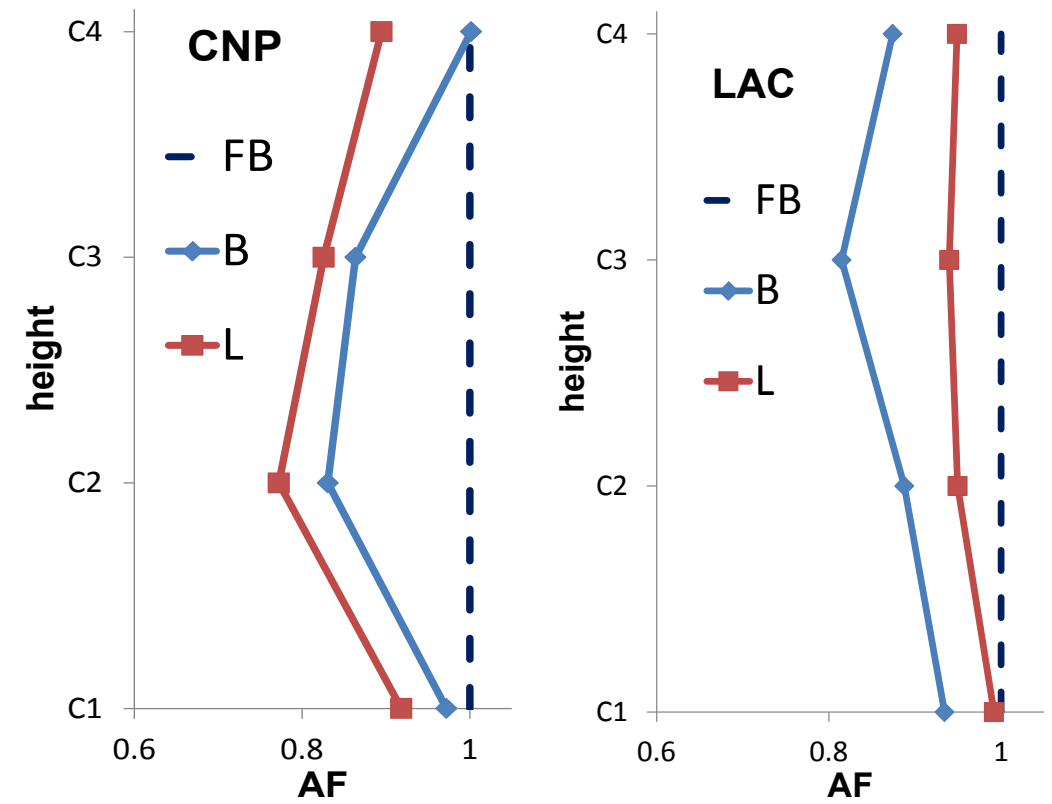

Figure 8. Amplification factor for L1-L4 and B1-B4 models (CNP and LAC motions).

Table 9

Maximum pseudoacceleration ratio [\%] (L models)

\begin{tabular}{lll}
\hline$\%$ & CNP & LAC \\
\hline L0 & 100 & 100 \\
L1 & 92 & 99 \\
L2 & 77 & 95 \\
L3 & 83 & 94 \\
L4 & 89 & 95 \\
L5 & 80 & 63 \\
L6 & 53 & 45 \\
\hline
\end{tabular}


Table 10

\begin{tabular}{lll}
\multicolumn{2}{l}{ Maximum pseudoacceleration ratio [\%] (B models) } \\
\hline$\%$ & CNP & LAC \\
\hline B0 & 100 & 100 \\
B1 & 97 & 94 \\
B2 & 93 & 89 \\
B3 & 86 & 82 \\
B4 & 99 & 87 \\
B5 & 98 & 85 \\
B6 & 86 & 76 \\
\hline
\end{tabular}

\section{Displacements}

Figure 9 shows the effects of isolation interfaces in terms of flexibility. First of all, comparing B1 and B0 maximum top displacements $(+70 \%$ for CNP and $+48 \%$ for LAC), it is possible to assess the increase in flexibility due to base isolation. Moreover, story isolated configurations (B2 and B3) show increase in flexibility if compared with fixed base building. B4 (added stories) is the only configuration that shows the same flexibility as the original B0 structure. Configurations B2 and B3 are more flexible than the original building but less than base isolated model (B1). B5 and B1 show close max displacements. Finally, B6 shows a big increase in flexibility if compared with other configurations. B6 top displacements result bigger than B1 and more than double if compared with B0. As deduced previously, comparing B5 and B6, it is possible to assess the importance of middle height isolation interface.
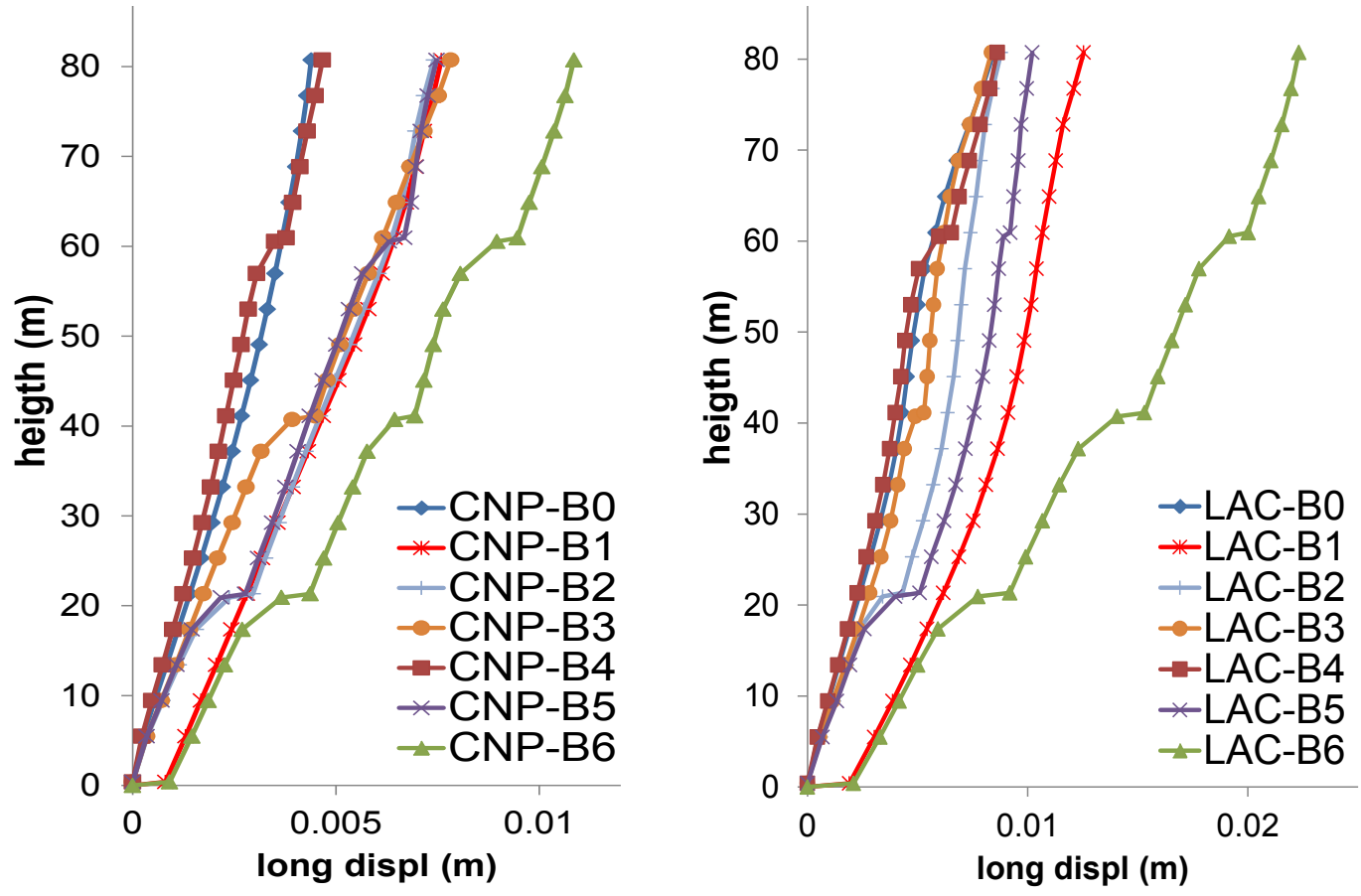

Figure 9. maximum displacement for B0-B6 models (CNP and LAC motions) 


\section{Conclusions}

The paper aims at assessing story isolation benefits from a structural point of view (fundamental periods, accelerations and displacements). This technique has been assessed considering several configurations including story isolated structures (configurations 2 and 3), added stories configurations (configurations 4) and segmental buildings (configurations 5 and 6). In particular, isolation interfaces have been introduced in those positions where shape modes show inflection points. Since no lab tests have been documented in literature on such structural problems, 3D printer technology has been applied in order to reproduce representative 3D scaled models (L models) on small indoor shake tables at University of California, San Diego. Modules versatility allows the introduction of several connectors able to simulate isolation interfaces in key locations along the height of the building. Comparison between numerical models and lab test models in terms of fundamental periods and top floor accelerations, showed good agreement.

In this regard, base isolation does not seem to create significant effects in decreasing maximum floor accelerations especially in upper levels. Results confirm that base isolation effectiveness decreases when superstructure flexibility increases, as described in Pochas and Pamboris, 2009 and Desai Amit and Gajjar, 2012.

The paper shows story isolation contributions in reducing spectral top accelerations, in comparison with base isolation. In particular, increase in structural flexibility due to isolation interfaces was shown to be significant especially in segmental building configurations.

Results in terms of displacements show how introducing interfaces along the height of the building affects the flexibility of various configurations. Both these two aspects (seismic forces reduction and increase in displacements) have to be taken into account when structural performance is assessed and designed.

In conclusion, this work can be considered a first attempt to investigate the possibility to reproduce story isolation on tall buildings adopting scaled 3D printer models. Isolation devices have been modelled with linear elastic behaviours and no damping has been considered. The validation of such technology with numerical simulations gave good agreement, fundamental for future investigations that can take into account more complex assumptions and improvements.

\section{Acknowledgement}

This study was possible thanks to professors Tara C. Hutchingson and Falco Kuester at University of California, San Diego who made possible to perform the lab tests and apply the 3D printer technology. The authors want to thank also Professor James M. Kelly from University of California, Berkeley. His assistance in the isolators properties definition gave determinant contributions to this paper.

\section{References}

Chang, K. C., Hwang, J. S., Wang, S. J., Lee, B. H. (2009).“Analytical and Experimental Studies on Seismic behavior of buildings with mid-story isolation.” ATC \& SEI 2009 Conference on improving the seismic performance of existing buildings and other structures.

Charmpis, D.C., Phocas, M.C., Komodromos, P. (2015) “ Optimized retrofit of multi-storey buildings using seismic isolation at various elevations: assessment for several earthquake excitations" Bulletin of Earthquake Engineering, $10.1007 / \mathrm{s} 10518-015-9737$.

Chey, M., Chase, J. G., Mander, J. B. and Carr, A. J. (2013).“Innovative seismic retrofitting strategy of added stories isolation system.’Front. Struct. Civ. Eng., 7(1): 13-23. 
Desai Amit, R. and Gajjar, R. K. (2012).“Structural control system for mid-rise building.”International journal of advanced engineering technology, Vol. III, II 30-33. E-ISSN 0976-3945.

Forcellini, D., Kelly, J., M. (2014). "The analysis of the large deformation stability of elastomeric bearings". Journal of Engineering Mechanics, ASCE, 10.1061: EM.1943-7889.0000729.

Kelly, J.M. (1997).“Earthquake-Resistant Design with Rubber.” 2nd ed., Springer-Verlag, London, England.

Kline, S.J. (1986). "Similitude and Approximation Theory", Springer-Verlag, New York, 1986.

Koh, T. and Kobayashi, M. (2000). "Vibratory Characteristics and Earthquake Response of Mid-Story Isolated Buildings" Memoirs of the Institute of Science and Technology, Meiji University, 39(12), 97-114.

Li, X.Z., Ou, H.L. and Lin, S. (2002). "Simplified Analysis on Calculation Model of Interlayer Sismic Isolation." Earthquake Engineering and Engineering Vibration, 22(1), 121-125.

Murakami, K., Kitamura, H., Ozaki, H. and Teramoto T. (2000)."Design and analysis of a building with the middle-story isolation structural system". Proceedings of the 12th World Conference of Earthquake Engineering. Auckland, New Zealand, Paper No. 0857

Ogura, K., Takayama M., Tsujita, O., Kimura, Y. and Wada, A. (1999). "Seismic response of Mid-Story Isolated Buildings." Journal of Structural and Construction Engineering, Architectural Institute of Japan, 56, 99-104.

Pan, T., and Cui, W. (1998)."Response of segmental buildings to random seismic motions."ISET Journal of Earthquake Technology, Paper No. 378, Vol. 35, No. 4, December 1998, pp. 105-112.

Pan, T.C,. Ling, S.F. and Cui, W. (1995)."Seismic Response of Segmental Buildings”. Earthquake Engineering and Structural Dynamics, Vol. 24, pp. 1039-1048.

Pan, T., and Cui, W. (1994)."Dynamic Analysis of Base-Isolated Shear Buildings”. Earthquake Engineering and Structural Dynamics, Vol. 23, pp. 1315-1329.

Phocas, M.C. and Pamboris, G. (2009). “Multi-storey structures with compound seismic isolation."Earthquake resistant engineering structures, VII. Transactions on the built Environment, Vol. 104.

Skinner, R.I., Robinson, W.H. and McVerry, G.H. (1993). “An introduction to seismic isolation.” John Willey\&Sons, New York, NY

Tasaka, M., Mori, N., Yamamoto, H., Murakami, K., and Sueoka, T. (2008).“Applying Seismic Isolation to Buildings in Japan Retrofitting and Middle-Story Isolation.”18th Analysis and Computation Specialty Conference, ASCE Structures Congress: pp. 1-11.

Tsuneki, Y., Torii, S., Murakami, K. and Sueoka T. (2008)."Middle-Story Isolated Structural System of High-Rise Building.” Proceedings of the 14th World Conference on Earthquake Engineering. Beijing, China, Paper No. S05-01-023.

Villaverde, R. (2002) “Aseismic roof isolation system: Feasibility study with 13-story building”. Journal of Structural Engineering, 10.1061/(ASCE)0733-9445(2002)128:2(188).

Villaverde, R., Aguirre, M., and Hamilton, C. (2005). "Aseismic Roof Isolation System Built with Steel Oval Elements: Exploratory Study." Earthquake Spectra, 10.1193/1.1850528, 225-241.

Xu, Z.G., Hu, M.Y. and Zhou, F.L. (2004). "Discuss on Mid-Story Isolation of Building," Earthquake Resistant Engineering and Retrofitting, 5, 23-28.

Zhou, F.L., Yang, Z., Liu, W.G., Tan, P (2004)."New seismic isolation system for irregular structure with the largest isolation building area in the world." Proceedings of the13th World Conference on Earthquake Engineering. 2004, Vancouver, B C, Canada, Paper No. 2349.

Ziyaeifar, M., Noguchi, H. "Partial mass isolation in tall buildings." Earthquake Engineering and Structural Dynamics, 1998, 27(1): 49-65. 